\title{
The substantia nigra and ventral tegmental area in Alzheimer's disease and Down's syndrome
}

\author{
W R G GIBB, * C Q MOUNTJOY, $\dagger$ D M A MANN, $\ddagger$ A J LEES* \\ From the Department of Neuropathology,* National Hospitals for Nervous Diseases, Maida Vale, London; \\ St Andrew's Hospital, $\uparrow$ Northampton; Department of Psychiatry, $\dagger$ Addenbrooke's Hospital, Cambridge and \\ Department of Pathology, $\ddagger$ University of Manchester, Manchester, UK
}

SUMMARY Degenerative changes in the substantia nigra and ventral tegmental area were investigated in 104 cases of Alzheimer's disease and 13 cases of Down's syndrome. Frequencies of tangles in three groups of patients with Alzheimer's disease were $86 \%, 44 \%$ and $46 \%$ (54\% overall) respectively. About half of those with tangles, but no Lewy bodies, had excess nigral cell loss, and $16 \%$ had moderate or severe neuronal fallout, but none had a Parkinsonian syndrome. Cases with nigral tangles were younger, tended to have more hippocampal and cortical tangles and plaques, and lower activities of cortical choline acetyltransferase. In most cases of Alzheimer's disease degeneration in nigral and tegmental areas was greater than controls, and tangles were evenly distributed. All the cases of Down's syndrome had tangles in the nigra and eight showed mild cell loss. Mild degenerative changes accompanied by tangles in the substantia nigra and ventral tegmental area are common in Alzheimer's disease, but severe cell loss is rare. When a Parkinsonian syndrome occurs in Alzheimer's disease it is likely to be due to Lewy body pathology.

In Alzheimer's disease (AD) neuronal loss and neurofibrillary tangle formation occur in the locus coeruleus $^{1-4}$ and raphé nuclei. ${ }^{56}$ In contrast, neuronal loss and tangle formation in the substantia nigra is said to be uncommmon, and when present tangles are confined to the medial substantia nigra. ${ }^{7}$ A recent review stated that tangles in the substantia nigra were rare in $A D$, but Lewy bodies were found in a few cases. ${ }^{8}$ The ventral tegmental area was said to show moderately frequent neurofibrillary tangles. There are no quantitative studies comparing the frequency and distribution of neurofibrillary tangles in the substantia nigra and ventral tegmentum in $\mathrm{AD}$, nor has the extent of cell damage been clearly documented. Reduction of dopamine levels in caudate nucleus and putamen ${ }^{9-11}$ suggest that nigral cell loss may be more extensive in $\mathrm{AD}$ than generally recognised.

It has also been suggested that some patients with Parkinsonian syndromes of unknown cause have nigral degeneration with tangles, ${ }^{12}$ representing either cases of previous encephalitis lethargica with sub-

Address for reprint requests: Dr W R G Gibb, Department of Neurology, Guy's Hospital, London SE1 9RT, UK.

Received 21 June 1988 and in revised form 24 September 1988. Accepted 27 September 1988 clinical infection, or cases of $\mathrm{AD}$ rather than Parkinson's disease.

In order to establish the frequency and severity of the pathology of AD in the the substantia nigra and ventral tegmental area we have studied 104 cases of $\mathrm{AD}$ and 13 cases of Down's syndrome. The extent of these pathological changes in the substantia nigra and ventral tegmental area has been related to histopathological and neurochemical markers of $\mathrm{AD}$ in the hippocampus and cerebral cortex.

\section{Materials and methods}

In this study the brains of 104 patients with $A D, 13$ patients with Down's syndrome and 31 controls without neurological disease or nigral pathology were examined. The cases of AD were obtained from three laboratories (Series 1-3) where the diagnosis was made on the basis of a history of progressive dementia associated with widespread cortical neurofibrillary tangles and senile plaques, in the absence of significant cerebrovascular disease. In Series 1 and the controls the whole brain was used, but in Series 2 and 3, and the cases of Down's syndrome, half-brains which had been cut midsagittally were employed (one half for histology; the opposite half frozen for biochemical study). Fixation was by immersion in $10 \%$ neutral formol saline for a minimum of three weeks.

In the 22 cases in Series 1 single midbrain blocks were 
prepared by cuts perpendicular to the axis of the brainstem, and tissue sections of $7 \mu \mathrm{m}$ thickness were stained with haematoxylin and eosin (H\&E). These sections were taken at the level of the oculomotor nerve. A series of 31 controls, aged 61-88 years, were prepared in the same way. The substantia nigra and ventral tegmental area, comprising the paranigral nucleus and central linear nucleus, were examined microscopically. Nigral cell counts were performed in one or two unilateral H\&E-stained sections by drawing around the limits of the substantia nigra, including the paranigral nucleus lying in the medial part, and counting the total number of pigmented cells using an eyepiece graticule at $x$ 400 magnification. Cells of the central linear nucleus were not counted, but in the substantia nigra and ventral tegmental area pigmented and non-pigmented cells were inspected for neurofibrillary tangles and Lewy bodies.

In Series 2, comprising 34 patients, unilateral transverse sections of the substantia nigra and ventral tegmental area between the oculomotor nucleus and decussation of the superior cerebellar peduncle were cut at $5 \mu \mathrm{m}$, and stained with H\&E and modified Palmgren's stain. ${ }^{13}$ The substantia nigra and paranigral nucleus were outlined with ink and each cell inspected for tangles and Lewy bodies. Samples of middle temporal cortex (Brodmann area 21) and hippocampus were cut at $5 \mu \mathrm{m}$ and stained with Palmgren's stain for quantitation of neurofibrillary tangles and senile plaques. The "nearest neighbour distance" method of Aherne and Diggle ${ }^{14}$ was used for density estimations of plaques and tangles in the middle temporal gyrus. ${ }^{15}$ In the hippocampus tangles and plaques were counted in whole sections.

In Series 3, comprising 48 cases, sections from the mid-part of the substantia nigra were cut at $16 \mu \mathrm{m}$ thickness and stained with H\&E and the Glees and Marsland modification of the Bielschowsky stain. Nigral sections were examined cell by cell. Samples of middle temporal gyrus (Brodmann area 21) and frontal cortex (Brodmann area 10) were stained with the Glees stain and used for counts of tangles and plaques, by the methods described by Mountjoy et al. ${ }^{16}$ The plaque count was combined from counts obtained in randomly selected parallel sweeps perpendicular to the cortical surface, and from counts obtained in selected areas containing the greatest number of plaques. The frequency of tangles was estimated on a four point scale $(0=$ absent, $1=$ slight, $2=$ moderate, 3 $=$ severe) after the method of Corsellis. ${ }^{17}$
Estimations of choline acetyltransferase (ChAT) were made in the equivalent areas of the middle temporal gyrus and frontal cortex of the opposite hemisphere. ${ }^{18}$

The cases of Down's syndrome were prepared by taking cortical blocks from all lobes, and one block of midbrain, cut transversely at the level of the oculomotor nucleus, from which $5 \mu \mathrm{m}$ sections were cut and stained with $H \& E$ and Palmgren's stain. The cerebral cortex was inspected for tangles and plaques and the substantia nigra studied as in AD Series 2.

In the cases of AD, Down's syndrome and controls examination of the substantia nigra and ventral tegmental area included estimations of the quantity of free melanin, of cell fragmentation and of the amount of cell loss, on a three point scale of mild, moderate and severe. The distribution of neurofibrillary tangles was noted in all cases and mapped on tracings of the substantia nigra in 11 cases in Series 1 .

\section{Results}

In AD Series 1 nineteen of the $22(86 \%)$ cases showed neurofibrillary tangles in the substantia nigra (table 1). The tangles were scarce (1-3 per section) in five cases $(23 \%)$, moderately frequent (4-9 per section) in six cases $(27 \%)$ and numerous ( $>10$ per section) in eight cases $(36 \%)$ (table 2$)$. The mean count of pigmented nigral cells in the controls was 859 (SD.206), whereas the mean count in 17 of the 19 tangle bearing cases, where the full extent of the nigra was included in the section, was 712 (SD.247) (difference not significant). In 14 cases without Lewy bodies in the substantia nigra the mean nigral cell count was 768 (SD.226) (ns), or $89 \%$ of the control value, and in the five Lewy body positive cases it was 568 (SD.195) (ns) or $66 \%$ of the control value. In six cases there were both Lewy bodies and tangles, of which three had moderate or severe nigral cell loss, two had mild cell loss and one had no cell loss. In 13 patients there were tangles, but no Lewy bodies, of which two had moderate or severe nigral cell loss, five had mild cell loss (of these seven patients, six showed numerous tangles) and six had no cell loss. No

Table 1 Selected clinical and pathological data in cases of Alzheimer's disease

\begin{tabular}{|c|c|c|c|c|}
\hline & Series I & Series 2 & Series 3 & Total \\
\hline $\begin{array}{l}\text { Number } \\
\text { Male } \\
\text { Female } \\
\text { Mean age at death (years) } \\
\text { Total number with tangles in substantia nigra } \\
\text { Number with tangles but no Lewy bodies in nigra } \\
\text { Nigral cell loss in cases with tangles alone: }\end{array}$ & $\begin{array}{l}22 \\
14 \\
8 \\
72 \cdot 3(38-87) \\
19 / 22(86 \%) \\
13 / 16(81 \%)\end{array}$ & $\begin{array}{l}34 \\
13 \\
21 \\
75 \cdot 9(48-92) \\
15 / 34(44 \%) \\
13 / 23(56 \%)\end{array}$ & $\begin{array}{l}48 \\
12 \\
36 \\
78 \cdot 0(63-99) \\
22 / 48(46 \%) \\
17 / 40(43 \%)\end{array}$ & $\begin{array}{l}104 \\
39 \\
65 \\
56 / 104(54 \%) \\
43 / 79(54 \%)\end{array}$ \\
\hline
\end{tabular}

LB, Lewy bodies. 
Table 2 Alzheimer's disease Series 1. Pathological findings in the substantia nigra

\begin{tabular}{|c|c|c|c|c|c|c|c|}
\hline Case & Age $(y r)$ & Sex & Free melanin & Cell loss & Lewy bodies & Tangles & Cell count \\
\hline $\begin{array}{l}1 \\
2 \\
3 \\
4 \\
5 \\
6 \\
7 \\
8 \\
9 \\
10 \\
11 \\
12 \\
13 \\
14 \\
15 \\
16 \\
17 \\
18 \\
19 \\
20 \\
21 \\
22\end{array}$ & $\begin{array}{l}38 \\
38 \\
61 \\
65 \\
66 \\
69 \\
69 \\
71 \\
71 \\
72 \\
72 \\
75 \\
77 \\
78 \\
78 \\
79 \\
80 \\
81 \\
87 \\
87 \\
87 \\
89\end{array}$ & $\begin{array}{l}\mathbf{F} \\
\mathbf{M} \\
\mathbf{F} \\
\mathbf{M} \\
\mathbf{M} \\
\mathbf{M} \\
\mathbf{M} \\
\mathbf{F} \\
\mathbf{M} \\
\mathbf{M} \\
\mathbf{M} \\
\mathbf{F} \\
\mathbf{F} \\
\mathbf{M} \\
\mathbf{M} \\
\mathbf{F} \\
\mathbf{M} \\
\mathbf{M} \\
\mathbf{F} \\
\mathbf{F} \\
\mathbf{M} \\
\mathbf{M}\end{array}$ & $\begin{array}{l}++ \\
+ \\
++ \\
+ \\
+ \\
+ \\
+ \text { to }++ \\
+ \\
+ \\
+ \\
+ \\
+ \\
++ \\
+ \\
+ \text { to }++ \\
+ \text { to }+ \\
++ \\
+ \\
++ \\
+ \\
++\end{array}$ & $\begin{array}{l}++ \text { to }+++ \\
++ \\
+++ \\
- \\
+ \\
+ \\
+ \\
+ \\
+ \\
- \\
+ \\
- \\
+ \\
+ \\
+ \\
+ \\
+ \\
++ \\
-\end{array}$ & $\begin{array}{c}+* \\
1 \\
0 \\
0 \\
0 \\
9 \\
0 \\
0 \\
0 \\
0 \\
0 \\
0 \\
0 \\
0 \\
2 \\
2 \\
10 \\
0 \\
0 \\
0 \\
0 \\
0\end{array}$ & $\begin{array}{r}6 \\
97 \\
20 \\
4 \\
13 \\
14 \\
5 \\
0 \\
13 \\
25 \\
2 \\
1 \\
23 \\
1 \\
5 \\
2 \\
1 \\
5 \\
20 \\
0 \\
7 \\
0\end{array}$ & $\begin{array}{c}-^{*} \\
453 \\
129 \\
171 \\
789 \\
628 \\
-{ }^{*} \\
674 \\
690 \\
790 \\
986 \\
950 \\
582 \\
1026 \\
857 \\
559 \\
341 \\
936 \\
736 \\
805 \\
693 \\
{ }^{*}\end{array}$ \\
\hline
\end{tabular}

$+=$ mild $++=$ moderate; $+++=$ severe

* Sections incomplete for cell counts.

patients showed Lewy bodies in the absence of tangles. Cases 15 and 22 did not show any cell loss, but had multiple falls and a shuffling gait respectively.

In $\mathrm{AD}$ Series 2 tangles were found in 15 of the 34 cases $(44 \%)$ (table 1$)$. Lewy bodies were also present in two of these 15 cases in whom there were only a few ( $<4$ per section) nigral tangles (one of these cases showed severe nigral cell loss, the other showed no cell loss). There was moderate or severe nigral cell loss in four of the 15 cases with tangles (one of which also had Lewy bodies). Of the 13 cases with tangles but no Lewy bodies, three had moderate cell loss, four had mild cell loss and six had no cell loss. One 69 year old male without tangles or Lewy bodies had severe nigral cell loss. The mean age of AD cases without tangles in the substantia nigra (79.2 years) was 11.8 years greater than in cases with nigral tangles ( 71.8 years). Comparison of tangle and plaque counts in the temporal lobe and hippocampus, showed that patients without nigral tangles had cortical and hippocampal plaque and tangle counts between $35 \%$ and $74 \%$ of the mean values of patients with nigral tangles (table 3).

In AD Series 3 twenty-two of the $48(46 \%)$ cases had nigral tangles, of which five also had nigral Lewy bodies (table 1). Of these five cases one had severe nigral cell loss, two had moderate and two had mild cell loss. Of the other 17 tangle cases without Lewy bodies two had moderate nigral cell loss, eight had mild cell loss and seven had no cell loss. One 90 year old female without tangles or Lewy bodies in the substantia had moderate nigral cell loss, although tangles were present in the locus coeruleus. Cases with tangles in the substantia nigra were marginally younger (6.1 years) than those without (table 4; columns 1 and 2). Estimations of tangle and plaque counts in the temporal and frontal cortex showed that the highest plaque counts occurred in cases with nigral tangles (tables 4, columns 1 and 3), but there was little difference in the tangle estimations. Activities of ChAT (columns 1 and 3) in temporal and frontal

Table 3 Alzheimer's disease Series 2. Temporal lobe and hippocampal plaque and tangle estimations in cases of Alzheimer's disease with and without tangles in the substantia nigra

\begin{tabular}{|c|c|c|c|}
\hline & $\begin{array}{l}\text { Group } 1 \\
\text { Tangles in substantia nigra }\end{array}$ & $\begin{array}{l}\text { Group } 2 \\
\text { Without tangles in substantia nigra }\end{array}$ & $\begin{array}{l}\text { Values in Group } 2 \\
\text { expressed as \% of Group } 1\end{array}$ \\
\hline $\begin{array}{l}\text { Number } \\
\text { Mean age (years) } \\
\text { Temporal cortex plaques* } \\
\text { Temporal cortex tangles* } \\
\text { Hippocampus plaques } \dagger \\
\text { Hippocampus tangles } \dagger\end{array}$ & $\begin{aligned} 12 & \\
70 \cdot 2 & \\
21 \cdot 4 & {[S D ~ 10 \cdot 8] } \\
22 \cdot 5 & {[\text { [SD 10.3] }} \\
66 \cdot 9 & \text { [SD 70.2] } \\
158 \cdot 3 & {[\text { [SD 87.5] }}\end{aligned}$ & $\begin{array}{l}\text { [SD } 11 \cdot 9] \\
\text { [SD } 9 \cdot 3 \text { ] } \\
\text { [SD } 14 \cdot 4 \text { ] } \\
\text { [SD } 84 \cdot 4 \text { ] }\end{array}$ & $\begin{array}{l}57 \% \\
59 \% \\
35 \% \\
74 \%\end{array}$ \\
\hline
\end{tabular}

*Temporal cortex plaque and tangle counts expressed as number per $\mathrm{mm}^{2}$.

†Hippocampal plaque and tangle counts expressed as number per section. 
Table 4 Alzheimer's disease Series 3. Estimations of tangles $(T)$ and plaques $(P)$, and choline acetyltransferase $(C h A T)$ in middle temporal gyrus (Brodmann area 21) and frontal cortex (Brodmann area 10) in patients with and without tangles in the substantia nigra. Cases with Lewy bodies excluded.

\begin{tabular}{|c|c|c|c|c|}
\hline & $\begin{array}{l}\text { Column } 1 \\
\text { Tangles in } S N \text { and } L C\end{array}$ & $\begin{array}{l}\text { Column } 2 \\
\text { Tangles in LC alone }\end{array}$ & $\begin{array}{l}\text { Column } 3 \\
\text { Tangles in SN ( LC NE) }\end{array}$ & $\begin{array}{l}\text { Column } 4 \\
\text { No tangles in } S N(L C N E)\end{array}$ \\
\hline $\begin{array}{l}\text { Number } \\
\text { Mean age (years) } \\
\text { P, B10 } \\
\text { P, B21 } \\
\text { T, B10 } \\
\text { T, B21 } \\
\text { ChAT, B10 } \\
\text { ChAT, B21 }\end{array}$ & $\begin{aligned} 6 & \\
72.5 & \\
1.5 & \text { [SD 0.84] } \\
2.8 & \text { [SD 2.6] } \\
1.7 & \\
2.3 & \\
2.9 & \text { [SD 1.7] } \\
1.3 & \text { [SD 1.9] }\end{aligned}$ & $\begin{array}{ll}10 & \\
78.6 & \\
1.0 & \text { [SD 1.4] } \\
1.8 & \text { [SD 2.8] } \\
0.6 & \\
2.2 & \\
3.6 & \text { [SD 4.5] } \\
2.6 & \text { [SD 2.4] }\end{array}$ & $\begin{aligned} 11 & \\
75 \cdot 7 & \\
1.1 & \text { [SD 0.91] } \\
2.0 & \text { [SD 2.2] } \\
1.3 & \\
2 \cdot 2 & \\
3 \cdot 1 & \text { [SD 1.5] } \\
2 \cdot 3 & \text { [SD } 1.4 \text { ] }\end{aligned}$ & $\begin{array}{ll}7 & \\
77.4 & \\
0.78 & \text { [SD 0.39] } \\
2.6 & \text { [SD 2.3] } \\
1.3 & \\
2.4 & \\
4.9 & \text { [SD 3.5] } \\
3.9 & \text { [SD 3.7] }\end{array}$ \\
\hline
\end{tabular}

Plaque counts derived from two measurements. ${ }^{16}$ Tangle counts on scale $1-4$, absent-severe. SN = substantia nigra; $L C=1$ locus coeruleus; $\mathrm{NE}=$ not examined. ChAT units, $\mu \mathrm{mol} / \mathrm{h} / \mathrm{g}$ protein. $\mathrm{B}=$ Broadmann area.

cortex were lower in those with nigral tangles.

Most cases of AD, with or without obvious cell loss in the substantia nigra and ventral tegmental area (paranigral nucleus and central linear nucleus), showed fragmentation of cells and dispersal of melanin granules in excess of that found in normal ageing (fig 1). Tangles were diffusely spread through the substantia nigra, paranigral nucleus and central linear nucleus. When their distribution was mapped in patients with small, moderate and large numbers they were found to be evenly spread in relation to cell groups in the medial to the lateral substantia nigra (fig 2). Brains showing Lewy bodies in the substantia nigra also contained Lewy bodies in the ventral tegmental area.

In the Down's syndrome patients there were numerous cortical tangles and plaques in all except Patient 1 who showed fewer tangles (table 5). All 13

Fig 1 Degenerating cells and extraneuronal melanin without obvious cell loss in the substantia nigra in a case of Alzheimer's disease. H\&E stain, $\times 512$. 


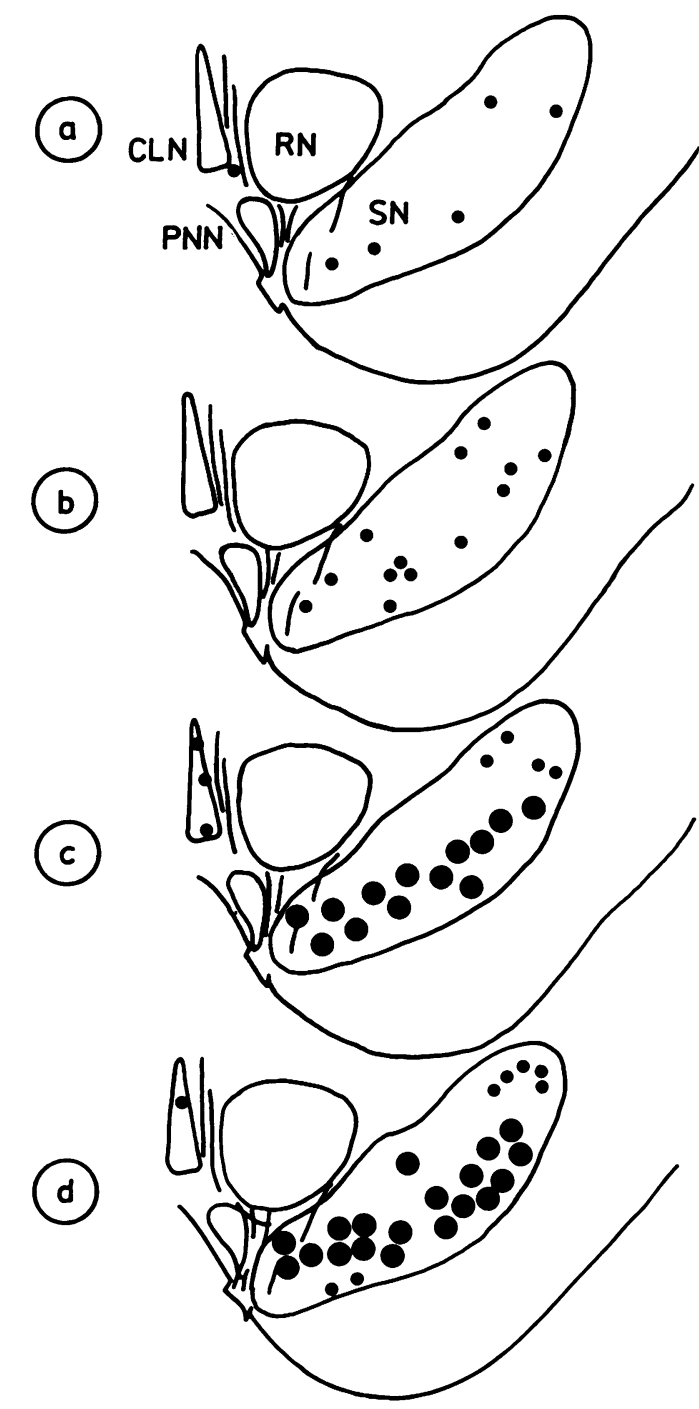

Fig 2 Mapping of tangles in left-sided sections of substantia nigra (SN) at the level of the oculomotor nerve and red nucleus (RN). The central linear nucleus (CLN), and paranigral nucleus ( $P N N$ ) which lies in the medial $S N$, form the ventral tegmental area. A-Four cases with 1-3 tangles per section. $B-T$ wo cases with 6-7 tangles per section. $C-$ Four cases with 10-25 tangles per section. D-Case 13 with 97 tangles (table 2). Small dots represent one tangle, large dots represent four or five tangles.

patients showed nigral tangles and these were usually more numerous than in $A D$ patients of the same age. In seven cases the amount of cell breakdown and dispersal of melanin in the substantia nigra was greater than that expected for normal ageing, and in eight cases there was mild cell loss. In every patient the tangles were distributed through the substantia nigra, paranigral nucleus and central linear nucleus, although they were sparse in Patients 1 and 2.

The morphology of the tangles in the substantia nigra or locus coeruleus in AD and Down's syndrome was identical. Well-developed tangles showed a coarse "rope-like" fibrillary component characteristic of the Alzheimer tangle which contains paired helical filaments (fig 3a). They were often globular, rather than flame-like in shape, and argyrophilic, but quite distinct from the skein-like, globose and less strongly argyrophilic tangle of the Steele-Richardson-Olszewski syndrome (fig 3b). The morphology of the Lewy bodies was identical to that in Parkinson's disease (fig 3c); in addition there were pale bodies, which fail to stain with conventional stains (fig $3 \mathrm{~d}$ ), and neurons with appearances resembling central chromatolytic change. In sections stained with $H \& E$ an occasional tangle, strongly argyrophilic in an adjacent section, appeared similar to or indistinguishable from the pale body of Parkinson's disease. Rarely tangles and Lewy bodies were found within the same cell.

\section{Discussion}

In this study the prevalence of neurofibrillary tangles in the substantia nigra of patients with $\mathrm{AD}$, in the absence of Lewy bodies, varied between $43 \%$ and $81 \%$ in the three series, with a mean of 54\% (43/79) (table 1). Excessive cell destruction with accumulation of free melanin pigment was common. Of these 43 patients with nigral tangles $44 \%$ showed no cell loss, $40 \%$ showed mild cell loss, $14 \%$ showed moderate cell loss and only one patient, a 61 year old woman, showed severe cell loss. In Series 1 the mean nigral cell count in patients with nigral tangles, but no Lewy bodies, was slightly reduced to $89 \%$ of the value obtained in 31 controls of similar mean age. Two patients with possible extrapyramidal signs showed no significant nigral pathology. In Series 2 and 3 the patients with tangles in the substantia nigra were 6 to 12 years younger and had more severe hippocampal, temporal and frontal lobe Alzheimer pathology than those without tangles. In addition, activities of ChAT in temporal and frontal cortex were lower (table 4, columns 1 and 3 ).

In keeping with these observations all the cases of Down's syndrome with cortical Alzheimer pathology showed nigral tangles. Over half the cases had excessive degrees of nigral cell destruction accompanied by mild cell loss.

The morphology of the tangles was mostly that of the rope-like Alzheimer tangle, characteristically found in the substantia nigra and locus coeruleus. Less 
Table 5 Selected clinical and pathological features in 13 cases of Down's syndrome

\begin{tabular}{|c|c|c|c|c|c|c|c|c|}
\hline Patient & Age (yr) & Sex & $\begin{array}{l}\text { Mental age/ } \\
I^{*}\end{array}$ & $\begin{array}{l}\text { Brain } \\
\text { weight }(g)\end{array}$ & $\begin{array}{l}\text { Nigral free } \\
\text { melanin }\end{array}$ & $\begin{array}{l}\text { Nigral } \\
\text { cell loss }\end{array}$ & Tangles & Cell count \\
\hline $\begin{array}{l}1 \\
2\end{array}$ & $\begin{array}{l}37 \\
41\end{array}$ & $\begin{array}{l}\mathbf{F} \\
\mathbf{M}\end{array}$ & $<2 / 30$ & $\begin{array}{l}1045 \\
1245\end{array}$ & $\stackrel{+}{+}$ & $\begin{array}{l}0 \\
0\end{array}$ & $\begin{array}{r}+ \\
1 \\
1\end{array}$ & $\begin{array}{l}\overline{930}(7 \mu \mathrm{m}) \\
612\end{array}$ \\
\hline $\begin{array}{r}3 \\
4 \\
5 \\
6 \\
7 \\
8 \\
9 \\
10 \\
11 \\
12 \\
13\end{array}$ & $\begin{array}{l}53 \\
57 \\
59 \\
60 \\
60 \\
62 \\
62 \\
64 \\
64 \\
65 \\
71\end{array}$ & $\begin{array}{l}\mathbf{M} \\
\mathbf{M} \\
\mathbf{M} \\
\mathbf{M} \\
\mathbf{F} \\
\mathbf{F} \\
\mathbf{F} \\
\mathbf{M} \\
\mathbf{M} \\
\mathbf{M} \\
\mathbf{M}\end{array}$ & $\begin{array}{rlr}3 & / & 30 \\
4 & / \\
4 & /<30 \\
& & \\
<2 & /<30 \\
6 & /<42 \\
3 & /<30 \\
2 & /<30 \\
<2 & /<30 \\
3.5 /<30 \\
2 & 44\end{array}$ & $\begin{array}{l}870 \\
\text { Not recorded } \\
950 \\
920 \\
965 \\
850 \\
960 \\
940 \\
940 \\
\text { Not recorded } \\
1130\end{array}$ & $\begin{array}{l}++ \\
++ \\
++ \\
++ \\
+ \\
+ \text { to }++ \\
+ \\
+ \\
+ \\
++ \\
++\end{array}$ & $\begin{array}{l}+ \\
+ \\
+ \\
(+) \\
+ \\
+ \\
0 \\
+ \text { to }(++) \\
+ \text { to }++ \\
+ \\
0\end{array}$ & $\begin{array}{l}13 \\
66 \\
46 \\
99 \\
35 \\
39 \\
16 \\
59 \\
11 \\
18 \\
17\end{array}$ & $\begin{array}{l}558 \\
403 \\
373 \\
495 \\
387 \\
403 \\
604 \\
211 \\
230 \\
450 \\
339\end{array}$ \\
\hline
\end{tabular}

$0=$ absent $+=$ mild $++=$ moderate. Moderate grades exceed that of controls.

* Based on the Wechsler Intelligence Test.

well-defined skeins of the globose tangle,,$^{19}$ characteristic of the Steele-Richardson-Olszewski syndrome were infrequent. ${ }^{20}$ The distribution of nigral pathology did not show predilection for the medial substantia nigra, inclusive of the paranigral nucleus, or for the central linear nucleus. In fact cases with mild, moderate and severe tangle formation showed changes spread diffusely through the ventral tegmental area and substantia nigra.

A number of clinical studies have emphasised that persons with AD often show extrapyramidal features, usually late in the course of the disease. Mild degrees of bradykinesia and muscular hypertonia are particularly common, and in one series were recorded in $61 \%$ of 65 patients. ${ }^{21}$ Axial rigidity, retropulsion and a positive glabellar tap were observed in five of nine patients. ${ }^{22}$ In contrast, patients with a clearcut Parkinsonian disorder complicating $\mathrm{AD}$ are uncommon and may be explained by the chance concurrence of Parkinson's disease. Indeed two large studies reporting the frequency of rest tremor in $\mathrm{AD}$ quote figures of $4 \%{ }^{23}$ and $10 \%,{ }^{24}$ which are considerably lower than suggested using poorly characterised signs such as slowness of movement and muscular stiffness.

Reduced amounts of dopamine and homovanillic acid have been found in the caudate nucleus in $\mathrm{AD},{ }^{9-11}$ although not in all studies. ${ }^{25-27}$ Caudate nucleus dopamine was lowered in four cases of Down's syndrome aged 53-57 years, though not in one aged 27 years. ${ }^{26}$ It has also been established that patients with Down's syndrome develop the neuropathological features of $\mathrm{AD}$, but at a younger age than normal. ${ }^{28-36}$

One previous histological study of the substantia nigra in $A D$ was done in six patients, all of whom had infrequent tangles, in contrast to the locus coeruleus, dorsal raphé nucleus and superior central nucleus, where tangles were more numerous. ${ }^{37}$ Another study found that nucleolar volume was normal in the substantia nigra, whereas this was reduced in the locus coeruleus. ${ }^{9}$ More recently cells of the substantia nigra were found to be reduced by $8 \%$ and their nucleolar volumes by $15 \% .^{38}$ Another study of four cases suggested much greater cell loss, ${ }^{39}$ but in neither study were cases with Lewy body degeneration excluded, and nerve cells containing tangles were infrequent. Cell counts in the ventral tegmental area in AD have been considered to be appreciably lower than in the substantia nigra, ${ }^{40}$ but no apparent difference was found in this study and no attempt was made to quantify cell loss in the paranigral nucleus or central linear nucleus.

In this study $54 \%$ of patients with AD had only tangles in the substantia nigra, about half of whom showed evidence of excessive loss of pigmented cells. Some $14 \%(6 / 43)$ had moderate degrees of cell loss, which might be sufficient to cause Parkinsonian features, but none was recorded. One unusual case (Patient 3, Series 1) had severe cell loss with tangles, but no Lewy bodies, and Parkinsonian features were absent. This evidence does not support the notion that neurofibrillary tangle degeneration in the substantia nigra is generally severe enough in $\mathrm{AD}$ to produce a Parkinsonian disorder or extrapyramidal signs. ${ }^{12}$ The estimations of nigral cell loss and results of cell counts clearly indicate that cases with Lewy bodies in the substantia nigra show greater cell depletion, emphasising the importance of excluding them in pathological and chemical studies intended for uncomplicated cases of AD. The relative frequency of Lewy bodies in patients with dementia and Alzheimer pathology, and the rarity of substantial (more than $60 \%$ ) nigral cell loss in uncomplicated AD suggests that Parkinsonian syndromes complicating $\mathrm{AD}$ are usually due to Lewy body pathology. Less common causes of a Parkinson- 
ian disorder and Alzheimer-type dementia are cortical Lewy body dementia, Pick's disease and corticobasal degeneration.

The study also shows that cases of AD with neurofibrillary tangles in the substantia nigra show more severe cortical Alzheimer pathology, lower activities of ChAT in cerebral cortex, and a younger age at death. This finding agrees with the well-established differences between early and late-onset $A D$, the early onset type showing more severe neuropathological and neurotransmitter abnormalities at cortical and subcortical locations. ${ }^{41}$

WRGG was a Medical Research Council Research Fellow at the time of this study. We thank Dr R O Barnard and Professor P L Lantos for permission to study their cases. We are grateful to Dr M N Rossor for providing the ChAT data, and for helpful discussions.

\section{References}

1 Tomlinson BE, Irving D, Blessed G. Cell loss in the locus coeruleus in senile dementia of Alzheimer type. J Neurol Sci 1981;49: 419-28.

2 Bondareff W, Mountjoy CQ, Roth M. Loss of neurons of origin of the adrenergic projection to cerebral cortex (nucleus locus coeruleus) in senile dementia. Neurology 1982;32:164-8.

3 Mann DMA, Yates PO, Hawkes J. The noradrenergic system in Alzheimer and multi-infarct dementias. J Neurol Neurosurg Psychiatry 1982;45:113-9.

4 Mann DMA, Yates PO, Hawkes J. The pathology of the human locus ceruleus. Clin Neuropathol 1983;2:1-7.

5 Curcio CA, Kemper T. Nucleus raphe dorsalis in dementia of the Alzheimer type: neurofibrillary changes and neuronal packing density. J Neuropathol Exp Neurol 1984;43:359-68.

6 Yamamoto T, Hirano A. Nucleus raphé dorsalis in Alzheimer's disease: neurofibrillary tangles and loss of large neurons. Ann Neurol 1985; 17:573-7.

7 Tomlinson BE, Corsellis JAN. Ageing and the dementias. In: Hume Adams J, Corsellis JAN, Duchen LW, eds. Greenfield's Neuropathology. London: Edward Arnold, 1984:951-1025.

8 Perry RH. Alzheimer's disease and related disorders. Br Med Bull 1986;42:34-41.

9 Mann DMA, Lincoln J, Yates PO, Stamp JE, Toper S. Changes in the monoamine containing neurones of the human CNS in senile dementia. Br J Psychiatry 1980;136:533-41.

10 Gottfries CG, Adolfsson R, Aquilonius SM, et al. Biochemical changes in dementia disorders of Alzheimer's type (AD/SDAT). Neurobiol Ageing 1983;4:261-71.

11 Arai $\mathrm{H}$, Kosaka K, lizuka T. Changes in biogenic amines and their metabolites in postmortem brains from patients with Alzheimer's type dementia. J Neurochem 1984;43:388-93.

12 Forno LS, Alvord EC. The pathology of parkinsonism. In: McDowell FH, Markham CH, eds. Recent Advances in Parkinson's Disease. Oxford: Blackwells, 1971:120-61.

13 Cross RG. Demonstration of neurofibrillary tangles in paraffin sections: a quick and simple method using a modification of Palmgren's method. Med Lab Sci 1982;39:67-9.

14 Aherne WA, Diggle PJ. The estimation of neuronal population density by a robust distance method. J Microsc 1978;114: 285-93.

15 Mann DMA, Yates PO, Marcyniuk B. Correlation between senile plaque and neurofibrillary tangle counts in cerebral cortex and neuronal counts in cortex and subcortical structures in Alzheimer's disease. Neurosci Lett 1985;56:51-5.
16 Mountjoy CQ, Roth M, Evans NJR, Evans HM. Cortical neuronal counts in normal elderly controls and demented patients. Neurobiol Ageing 1983;4:1-11.

17 Corsellis JAN. Mental Illness and the Ageing Brain. Maudsley Monographs Number 9. London: Oxford University Press, 1962.

18 Rossor MN, Garrett NJ, Johnson AJ, Mountjoy CQ, Roth M, Iversen $L L$. A post-mortem study of the cholinergic and GABA systems in senile dementia. Brain 1982;105:313-30.

19 Hirano A, Malamud N, Kurland LT. Parkinsonism-dementia complex, an endemic disease on the island of Guam. IIPathological features. Brain 1961;84:662-79.

20 Steele JC, Richardson JC, Olszewski J. Progressive supranuclear palsy. Arch Neurol 1964;10:333-59.

21 Pearce J. The extrapyramidal disorder of Alzheimer's disease. Eur Neurol 1974;12:94-103.

22 Drachman DA, Stahl S. Extrapyramidal dementia and levodopa. Lancet 1975;i:809.

23 Sulkava R. Alzheimer's disease and senile dementia of Alzheimer type. A comparative study. Acta Neurol Scand 1982;65:636-50.

24 Mölsä PK, Marttila RJ, Rinne UK. Extrapyramidal signs in Alzheimer's disease. Neurology 1984;34:1114-6.

25 Yates CM, Allison Y, Simpson J, Maloney AFJ, Gordon A. Dopamine in Alzheimer's disease and senile dementia. Lancet 1979;ii:851-2.

26 Yates CM, Simpson J, Gordon A, Maloney AFJ, Allison Y, Ritchie IM, Urquhart A. Catecholamines and cholinergic enzymes in pre-senile and senile Alzheimer-type dementia and Down's syndrome. Brain Res 1983;280:119-26.

27 Cross AJ, Crow TJ, Johnson JA, et al. Monoamine metabolism in senile dementia of Alzheimer's type. J Neurol Sci 1983;60 383-92.

28 Olson MJ, Shaw CM. Presenile dementia and Alzheimer's disease in mongolism. Brain 1969;92:147-56.

29 Burger PG, Vogel FS. The development of the pathological changes of Alzheimer's disease and senile dementia in patients with Down's syndrome. Am J Pathol 1973;73:457-68.

30 Ellis WG, McCullough JH, Corley CL. Presenile dementia in Down's syndrome. Neurology 1974;24:101-6.

31 Price DL, Whitehouse PJ, Struble RG, et al. Alzheimer's disease and Down's syndrome. Ann NY Acad Sci 1982;396:145-64.

32 Mann DMA, Yates PO, Marcyniuk B. Senile dementia of Alzheimer type and Down's syndrome in middle age form an? age related continuum of pathological changes. Neuropathol Appl Neurobiol 1984;10:185-207.

33 Mann DMA, Yates PO, Marcyniuk B, Rawndra CR. Pathologica evidence for neurotransmitter deficits in Down's syndrome of middle age. $J$ Ment Defic Res 1985;29:125-35.

34 Wisniewski KE, Wisniewski HM, Wen GY. Occurrence of neuropathological changes and dementia of Alzheimer's disease in Down's syndrome. Ann Neurol 1985;17:278-82.

35 Wisniewski KE, Dalton AJ, Crapper McLachlan DR, Wen GY, Wisniewski HM. Alzheimer's disease in Down's syndrome clinicopathological studies. Neurology 1985;35:957-61.

36 Casanova MF, Walker LC, Whitehouse PJ, Price DL. Abnormalities of the nucleus basalis in Down's syndrome. Ann Neurol 1985;18:310-3.

37 Ishii T. Distribution of Alzheimer's neurofibrillary changes in the brain stem and hypothalamus of senile dementia. Acto Neuropathol 1966;6:181-7.

38 Mann DMA, Yates PO, Marcyniuk B. Monoaminergic systems in presenile Alzheimer's disease and senile dementia of Alzheimer type. Clin Neuropathol 1984;3:199-205.

39 Tabaton M, Schenone A, Romagnoli P, Mancardi GL. A quantitative and ultrastructural study of substantia nigra and nucleus centralis superior in Alzheimer's disease. Acta Neuropathol 1985;68:218-23.

40 Mann DMA, Yates PO, Marcyniuk B. Dopaminergic neurotransmitter systems in Alzheimer's disease and in Down's syndrome at middle age. J Neurol Neurosurg Psychiatry 1987;50:341-4.

41 Roth $M$. The association of clinical and neurobiological findings and its bearing on the classification and aetiology of Alzheimer's disease. Br Med Bull 1986;42:42-50. 